\title{
Socio-demographic factors of early sexual debut and depression among adolescents
}

\author{
Dorothy Ebere Adimora, Alexandra Okezie Onwu
}

Department of Educational Foundations, Educational Psychology Unit, Faculty of Education, University of Nigeria, Nsukka, Nigeria.

\section{Emails:}

ebere4jesus@yahoo.com, lexandra@yahoo.com

\begin{abstract}
Background: Adolescent early sexual debut as it relates with socio-demographic factors and depression of secondary school adolescents. During the adolescent stage, attitudes, values and behaviours that shape a young person's behavior in the future develop. Age of sexual debut is generally low, yet there is dearth of knowledge on sexuality in the area of this study-Nsukka Education zone of Enugu State, Nigeria.

Objective: To determine the socio-demographic factors of early sexual debut and depression among adolescents in secondary schools in Nsukka Education zone of Enugu state, Nigeria.

Materials and methods: A cross-sectional longitudinal study of 408 secondary school adolescents in Nsukka Education zone of Enugu state, Nigeria during the 2016/2017 school year. Data was collected using pre-tested, observation schedule, structured interview and well-structured questionnaire. Tests of statistical significance were carried out using chi-square and t-tests. A $\mathrm{p}$ value of $<0.005$ was found to be significant."

Results: The age group at which respondents had their first sexual intercourse ranged between 13 to 19 years, the mean ages are 12.1 \pm 1.2 and $14.5 \pm 1.5$ for males and females, while the modal and median ages at first sexual intercourse for male and female are 14 and 13 years respectively with a cumulative frequency percent of 56.5. The girls-initiated sex earlier than the boys $(p=0.001)$. Those brought up by one parent-initiated sex at an earlier age $(\mathrm{p}=0.000)$, while age of sex initiation increased with maternal $(\mathrm{p}=$ $0.000)$ and paternal education $(\mathrm{p}=0.001)$. Depressed adolescent boys and girls were more likely than their non-depressed peers to have experienced sexual intercourse. The youngest adolescents who were depressed were more likely to have experienced intercourse than the older ones who were not depressed. Respondents sharing room with parents or adult relations of opposite sex were found to have initiated sex earlier than those staying alone or sharing room with same sex peers.

Conclusion: Age at sexual debut was found to be associated with younger age, gender, living with a one parent and parents' educational status.
\end{abstract}

Keywords: Adolescents, depression, family factors, sexual initiation.

DOI: https://dx.doi.org/10.4314/ahs.v19i3.39

Cite as: Adimora DE, Onwu AO. Socio-demographic factors of early sexual debut and depression among adolescents. Afri Health Sci. 2019;19(3): 2634-2644. https:// dx.doi.org/10.4314/ahs.v19i3.39

\section{Introduction}

Adolescence is a remarkable time in terms of reaching sexual and mental maturity. Adolescent is defined by the World Health Organization (WHO) as a person aged be-

\section{Corresponding author: \\ Dorothy Ebere Adimora, \\ Department of Educational Foundations, \\ Educational Psychology Unit, Faculty of \\ Education, University of Nigeria, \\ Nsukka, Nigeria. \\ Email: ebere.adimora@unn.edu.ng}

tween 10 to 19 years $^{1}$. Adolescence is a progression from appearance of sexual characteristics to sexual and reproductive maturity; development of adult mental processes, adult identity and a period of transition from total socio-economic dependence to relative independence ${ }^{2}$.

Limited research shows that a good number of adolescents indulge in early sexual debut, the incidence of pregnancies among them is high ${ }^{1}$. Most of them face the risk of induced abortions under unsafe conditions, and contract sexually transmitted infections including human immune deficiency virus (HIV), whilst, some are predisposed to the risk of vesico-vagina fistulae (VVF) 
and Cephalo Pelvic Disproportionate (CPD) - a medical condition which means that the head of the baby is too big to pass through the mother's pelvic cavity especially if the mother is still an adolescent, it makes them pass urine at random, and also Recto Vagina Fistulae (RVF) when feaces escape uncontrollably through the opening between the vagina and the rectum of a woman who delivers a baby under such situation ${ }^{3}$.

Sexual debut simply refers to when the adolescent had the first sexual experience. Everyone should be able to make informed decisions about their sexual life. Deciding to wait until one is fully ripped means taking ownership of one's body and future that is called a "delayed or late" sexual debut which means waiting a little longer before having sex. By current national norms, debut is considered "early" if it occurs prior to age 15, "normative" if it occurs between 15 and 19 years of age, and "late" if it occurs after 19 years of age 4 . Early sexual debut increases the risk for teen pregnancy and STIs including HIV. About 16 million adolescent girls aged 15-19 give birth each year, roughly $11 \%$ of all births worldwide and almost $95 \%$ of these births occur in developing countries ${ }^{1}$.

However, early sexual debut is referred to as having had first sexual intercourse at or before age $14^{5}$. Some authors reveal that early sexual debut is commonly defined as having had first sexual intercourse at or before age 14 years which is associated with risks to sexual and reproductive health $^{6}$. Early sexual debut may not only increase the length of time in adolescence in which a young woman can become pregnant or the young man becomes sexually active, but is associated with experiences of sexual coercion and violence as well ${ }^{5}$. It may lead to premature pregnancy, depression and increased sexual risk-taking behaviour, such as having multiple partners and not using contraceptives, also may be independently associated with pregnancy ${ }^{5}$.

Early sexual debut is also attributed to some factors such as growing up in single-parent-, step-, or cohabiting families. These have been reported to have negative effects on adolescents' sexual behaviour ${ }^{7}$. A report shows that with the exception of girls in single parent families, family structure does not significantly influence adolescents' sexual initiation ${ }^{8}$. It was postulated that the family structure and context, more specifically the mother-child relationship, their level of interaction, and the mother's attitudes towards and discussion of sex is associated with adolescents' sexual debut ${ }^{8}$. A study shows that adolescents who lived with both parents at 14 years were less likely to have initiated first intercourse by 15 years; however, after 16 years, family structure had less effect ${ }^{9}$. Early sexual debut has been associated with higher number of lifetime sexual partners, increased risk of papilloma virus infection, cancer of the cervix and death due to abortion and teenage pregnancies. It has been observed that adolescents in Nigeria engage in sex at earlier age.

Early sexual debut is connected with multiple sexual risk behaviours such as inconsistent use of condoms and greater number of sexual partners ${ }^{10}$. This places early initiators at higher risk for sexually transmitted diseases and pregnancy ${ }^{10}$. Having first intercourse before 15 years is connected, for example, with suicidal ideation ${ }^{11}$.

According to World Bank Group ${ }^{14}$, a global analysis examining socio-economic status in relation to adolescent sexual and reproductive health (ASRH) outcomes in Bangladesh, Burkina Faso, Ethiopia, Nepal, Niger, and Nigeria, at least one-quarter of adolescent females 15-19 years of age are married in the countries studied ${ }^{14}$. Fifty percent of adolescents 15-19 years of age have given birth in the countries studied. Less than $50 \%$ of married adolescents aged 15-19 years of age use modern contraception in the countries studied. Almost $40 \%$ of married adolescent females have had sexual intercourse before age 15 in Nigeria, Bangladesh, and Niger. Adolescents (10-19 years of age) in the world especially in African countries particularly in Nigeria, face tremendous challenges of early sexual debut, such as depressive disorders ${ }^{15}$.

Rates of youthful depressive disorders are high worldwide especially in Nigeria ${ }^{16}$. Sexually experienced adolescents displayed more depressive symptoms than their sexually abstinent peers ${ }^{16}$. Stress associated with sexual activity plays a causal role in the development of adolescent depressive disorders ${ }^{12}$. It was asserted that adolescent early sexual debut and relationships are often marked by breakups, unmet needs for intimacy, and feelings of rejection, and they may require sophisticated conflict management skills few adolescents have mastered ${ }^{17}$. Individuals vary in their coping strategies and resources, and those adolescents who either lack or do not utilize effective coping mechanisms to navigate romantic difficulties may be particularly at risk for depression ${ }^{17}$. 
Depression is the most common form of emotional problems experienced during adolescence, it can be characterized by feelings of sadness, anxiety, fear, guilt, anger, contempt and confused thinking ${ }^{18}$. It has been shown that most adults who experience recurrent episodes of depression had an initial depressive episode as teenag$\operatorname{ers}^{19}$. The ability to engage positively in intimate sexual contact likely requires a certain emotional maturity which is not yet developed in the majority of early and middle adolescents, thus sexual activity across the early and middle adolescent years is associated with self-reported depression and more likely indicates developmental difficulties than rapid and successful adolescent passage ${ }^{20}$.

However, it seems Nigeria and particularly secondary school administrators in Enugu State are not yet aware of turbulences of adolescence stage triggered by hormonal changes, prevalence of dramatic and drastic developments at this stage of life especially when they have romantic difficulties. There is also a dearth of knowledge on sexuality in the area of this study which is needed for a proper monitoring and guidance of the adolescents to avert early sexual debut from adversely influencing their lives. Some adolescents in Enugu State are exposed to early sexual debut and consequently encounters problems which result in depression.

It has been observed that much is not yet known about the extent to which sexual debut and socio-demographic factors relate with depression symptoms. This therefore, makes this study imperative. The problem of this study in a question form is: How does the adolescents' sexual debut relate with socio-demographic factors and depression symptoms?

This study, therefore, seeks to explore the adolescent sexual debut as it relates with socio-demographic factors and depression symptoms.

\section{Measures}

\section{Early sexual debut}

Early sexual activity was elicited by measure of respondents' report that they never had sex and also their report that they had had sex. The researchers defined early sex as intercourse before or by age 13. This study focused on the timing of adolescent-reported first oral, vaginal, and/ or anal sexual experience with $\leq 19$ years of age defined as early debut and $\leq 19$ years of age defined as later debut. We chose age 13 as the cut-off because it is below the national median age of first sexual intercourse at 19 years ${ }^{17}$, and it is at the median age of first sexual activity (oral, vaginal, and anal) in our high-risk sample. Moreover, research indicates that first sex prior to age 13 is associated with a high number of lifetime sexual partners, a key factor in the spread of STDs, HIV/AIDS and experience of VVF and RVF. By restricting our sample to the group of sexually inexperienced youth aged 13-19 years, we were able to reach those who first had sex between waves, when they were aged 13-19 years. We included several social and demographic variables. Age and sex were measured as continuous variables. Also included were family type, living with opposite sex in the same room, questions on whether the respondent had a mother or father figure in his or her life and was living with one or both of them.

\section{Self-rating depression}

Depression was assessed using the CDI developed by Maria Kovacs. The CDI was designed to measure self-rated, symptom-oriented assessment of depressive symptoms for school age children and adolescents. Sub-scales in the CDI included negative mood, interpersonal problems, ineffectiveness, anhedonia (the inability to gain pleasure from normally pleasurable experiences) and negative self-esteem. It covers the consequences of depression as they relate to children and functioning in school and with peers ${ }^{19}$. A reliability coefficient of 0.86 was reported for the scale and found to be a valid measuring device when compared with other instruments ${ }^{20}$. For each of the 27 items, the participant has three possible answers; 0 indicating an absence of symptoms, 1 indicating mild symptoms, and 2 indicating definite symptoms. The total score ranged from 0 to 54, with higher scores representing more severe depressive symptomatology. Participants were classified according to cut-offs proposed by ${ }^{20}$, which minimise the risk of false positives, whereby a CDI score of 0 indicates no symptoms, scores 1-19 indicate 'mild to moderate' depressive symptoms and scores equal to or above 20 indicate 'definite caseness ${ }^{20,21}$. This classification was applied since there was no specific cut-off point for CDI based on studies carried out on Nigerian adolescents. ${ }^{19}$ argued that a lower cut-off point is only usually suggested for populations where high rates of depression are expected. 


\section{Methods}

Following approval by University of Nigeria, Nsukka, Ethical Committee for Non-Clinical Research Involving Human Subjects, a cross-sectional analysis of the baseline assessment of a longitudinal study among early adolescents was adopted for the study. The study was carried out in the six Education zones in Enugu state, Nigeria which is divided into six education zones namely: Agbani, Awgu, Enugu, Nsukka, Obollo-Afor and Udi. All the senior secondary adolescents in 285 secondary schools in Enugu State, Nigeria in 2016/2017 academic sessioncomprised the popultion of this study. The target population is students in Senior Secondary class II, (SS11) which constitute one-sixth of the entire student population in Enugu State, Nigeria. A multi stage sampling technique was employed to draw a sample of 408 secondary school adolescents. An observation schedule and structured interview session and well-structured questionnaire were used to obtain information on sociodemographic factors of early sexual debut and depression among adolescents in secondary schools. Data was collected through the help of 8 research assistants. The instruments were validated by experts. The reliability coefficient of the instruments were ascertained by subjection to field trial. The adolescents were interviewed and completed questionnaire on their early sexual debut and depression.

\section{Study design and population}

A cross-sectional study was conducted in selected schools of Enugu State, Nigeria from May - June 2017. The study population consisted of secondary school adolescents aged 13-19 years living and studying in various secondary schools in the area. Enugu state is one of the states at the Eastern region of Nigeria with six Education zones of 334 public secondary schools in urban and rural locations. A multistage random sampling technique was employed in the selection of the participants in this study. A list of all public schools was obtained from the region. Simple random sampling technique was used to select one class each from the 285 schools, stratified random sampling technique was used to select two students from 130 schools and one student each from 25 schools. Sampling from each class was done proportional to the size of the class. A self-administered structured questionnaire was administered to consenting adolescent in the schools used in this study. The questionnaires collected informa- tion on socio-demographic, family and peer characteristics. Information on socio-demographic variables, age at sexual debut, depression of the adolescents was collected. All the information was collected in class under the supervision of trained research assistants in the absence of the teachers.

\section{Data analysis}

Data were double entered into statistical Software for Social Scientists version 15 and later transferred in to STATA version 11.2 statistical software for analysis. Frequencies were run for all categorical variables whilst means and standard deviation were calculated for continuous variables to examine sample characteristics. Differences between proportions were examined using Chi square test and Student t-test was used to compare differences between means. Survival analysis was employed to examine time to age at sexual debut. The adolescents who never had sex at all or had sex after age 13 were considered censored. Log-rank test was used to compare the rate (incidence) of sexual debut in different groups of predictors. Considering time to event (sexual debut) nature of the analysis, Cox regression models were then built to examine sexual debut hazards ratios in different predictor variables. Different adjusted Cox regression nested models were run to adjust for various confounders and the best parsimonious model was chosen based on the log-likelihood ratio test. Due to differences between males and females with regard to early sexual debut and bivariate analysis, analyses for male and females was done separately. All the analyses were two tailed and type- 1 error rates was set at $5 \%$ level.

Prevalence of self-rated depression and experience of sexual intercourse were calculated for both boys and girls. Bivariate associations between having experienced sexual intercourse and self-rated depression were examined by cross-tabulations and significance was tested. Odds ratios for having experienced sexual intercourse according to self-rated depression with exact age as continuous variable were calculated with logistic regression separately for boys and girls. An additional model with gender and its interaction with self-rated depression was developed to measure the differences between boys and girls. All the analyses were stratified by age group from 13-19 years. Finally, socio-demographic variables were controlled for. 


\section{Ethical consideration/approval}

The study was approved by the Research Ethical Committee of University of Nigeria, Nsukka ethical clearance committee. Verbal and written consent was obtained from each participant prior to data collection.

\section{Results}

Table 1. Proportions $(\%(\mathrm{n} / \mathrm{N}))$ of those having experienced sexual intercourse by age.
Sexual experience and self-reported depression of adolescents across the years

In the whole sample, $39.1 \%$ of the girls and $34.4 \%$ of the boys had experienced sexual intercourse. Moderate or severe self-reported depression was found in $7.9 \%$ of the boys $18.2 \%$ of the girls. In the whole sample, $42.5 \%$ of depressed adolescents had had sexual intercourse, while among non-depressed respondents the figure was only $36.1 \%$. The proportion of those who had experienced intercourse increased chronologically from 13 to 19-yearolds among both boys and girls (Table 1).

Table 1. Proportions $(\%(n / N))$ of those having experienced sexual intercourse by age. Sexual experience and self-reported depression of adolescents across the years

$\begin{array}{lll}\text { Age (years) } & \text { Boys } & \text { Girls } \\ 13 & 14.1(1902 / 14,262) & 13.2(1965 / 15,178) \\ 14 & 22.4(5104 / 23,436) & 24.5(5714 / 24,034) \\ 15 & 36.1(7732 / 21,895) & 38.9(8956 / 22,429) \\ 16 & 45.9(9573 / 20,058) & 55.8(11,017 / 20,058) \\ 17 & 57.8(4884 / 8432) & 62.7(5228 / 8051) \\ 18 & 72.5(819 / 1151) & 77.9(1333 / 1672) \\ 19 & 74.5(249 / 337) & 78.9(572 / 710)\end{array}$

The association between experience of sexual intercourse and self-reported depression can be seen in Table 2. Among both boys and girls, in the youngest age groups depressed adolescents were more likely than their peers to have experienced sexual intercourse. The association was highly significant in the age groups 13 to 17 years, although it remained significant $(\mathrm{p} \leq 0.05)$ among 18-yearold girls. 
Table 2. Proportions $(\%(n / N))$ of those having experienced sexual intercourse among depressed and non-depressed adolescents by age

\begin{tabular}{lllllll}
\multicolumn{2}{c}{ Boys } & & & Girls & & \\
& & & & & \\
& Depressed & Non-depressed & P-value & Depressed & Non-depressed & P-value \\
Age & & & & & & \\
& & & & & & \\
13 & $24.9(682 / 2864)$ & $12.4(1283 / 12,311)$ & $\leq 0.001$ & $36.7(384 / 1017)$ & $12.1(1515 / 13,241)$ & $\leq 0.001$ \\
14 & $36.1(1565 / 4446)$ & $23.2(4149 / 19,588)$ & $\leq 0.001$ & $40.4(749 / 1895)$ & $20.2(4355 / 21,540)$ & $\leq 0.001$ \\
15 & $48.3(1727 / 3633)$ & $36.4(7228 / 18,795)$ & $\leq 0.001$ & $44.5(748 / 1639)$ & $35.3(6985 / 20,255)$ & $\leq 0.001$ \\
16 & $56.9(1707 / 2958)$ & $55.2(9308 / 17,097)$ & 0.001 & $50.8(719 / 1441)$ & $48.5(8855 / 18,615)$ & 0.090 \\
17 & $63.8(800 / 1232)$ & $66.1(4428 / 6819)$ & 1.000 & $59.1(435 / 722)$ & $56.5(4457 / 7708)$ & 0.222 \\
18 & $79.0(241 / 313)$ & $78.3(1092 / 1359)$ & 0.186 & $62.3(104 / 164)$ & $74.1(715 / 987)$ & 0.020 \\
19 & $82.3(103 / 127)$ & $78.3(469 / 583)$ & 1.000 & $81.0(49 / 62)$ & $71.9(200 / 275)$ & 0.341
\end{tabular}

Table 3. Odds ratios (OR, 95\% CI) for having experienced sexual intercourse according to depression and exact age(continuous), stratified for age groups (Model 1).

Odds ratios of having experienced intercourse according to self-reported depression and controlled for exact age are shown in Table 3 . The strongest relation was found among the youngest boys among whom those who were depressed were almost five times more likely to have experienced intercourse than those who were not depressed (Table 3). Among the boys in the 18-year-old group, those who were depressed were less likely to have experienced intercourse than those who were not depressed, but the association was not seen among those of 19 -year-old. As seen in Table 3, the odds ratios by depression for having experienced sexual intercourse were greater among boys than among girls in the age groups 13 and 14. Adding to the models' family structure, mother's education and father's education did not change the associations detected between depression and having experienced sexual intercourse otherwise, but the association was $\mathrm{P}=0.002$ statistically significant among 15 -year-old girls. The odds ratios for having experienced intercourse by depression had a slight modification, but some of those revealed to be significant $-\mathrm{P}=0.000$, associations persisted as significant $\mathrm{P}=0.000$ when socio-demographic variables were controlled. 


\begin{tabular}{|c|c|c|c|c|}
\hline \multirow{3}{*}{13} & \multicolumn{2}{|c|}{ Model 1: Depression and age } & \multicolumn{2}{|c|}{$\begin{array}{l}\text { Model 2: Depression and age, controlled for } \\
\text { sociodemographic variables }\end{array}$} \\
\hline & Boys & Girls & Boys & Girls \\
\hline & & & & \\
\hline Depression & $2.7(2.4-3.0)$ & $4.7(4.1-5.4)$ & $2.5(2.2-2.8)$ & $4.4(3.8-5.1)$ \\
\hline Age (continuous) & $2.1(1.6-2.7)$ & $1.8(1.4-2.3)$ & $2.0(1.5-2.6)$ & $1.8(1.3-2.3)$ \\
\hline \multicolumn{5}{|l|}{14} \\
\hline Depression & $2.7(2.4-3.0)$ & $4.7(4.1-5.4)$ & $2.5(2.2-2.8)$ & $4.4(3.8-5.1)$ \\
\hline Age (continuous) & $2.1(1.6-2.7)$ & $1.8(1.4-2.3)$ & $2.0(1.5-2.6)$ & $1.8(1.3-2.3)$ \\
\hline \multicolumn{5}{|l|}{15} \\
\hline Depression & $1.5(1.4-1.6)$ & $1.6(1.5-1.8)$ & $1.4(1.3-1.5)$ & $1.5(1.4-1.7)$ \\
\hline Age (continuous) & $2.3(2.1-2.5)$ & $1.9(1.8-2.1)$ & $2.3(2.1-2.6)$ & $2.0(1.8-2.2)$ \\
\hline \multicolumn{5}{|l|}{16} \\
\hline Depression & $1.1(1.1-1.2)$ & $1.1(1.0-1.2)$ & $1.1(1.0-1.2)$ & $1.0(0.9-1.1)$ \\
\hline Age (continuous) & $1.9(1.7-2.1)$ & $1.7(1.6-1.9)$ & $1.9(1.7-2.1)$ & $1.7(1.6-1.9)$ \\
\hline \multicolumn{5}{|l|}{17} \\
\hline Depression & $1.0(0.9-1.1)$ & $1.1(0.9-1.3)$ & $0.9(0.8-1.1)$ & $1.0(0.9-1.2)$ \\
\hline Age (continuous) & $1.9(1.6-2.4)$ & $2.0(1.6-2.4)$ & $1.6(1.3-2.0)$ & $1.9(1.5-2.3)$ \\
\hline \multicolumn{5}{|l|}{18} \\
\hline Depression & $0.8(0.6-1.1)$ & $0.7(0.5-0.9)$ & $0.7(0.5-1.0)$ & $0.7(0.4-1.0)$ \\
\hline Age (continuous) & $1.4(0.9-2.1)$ & $0.8(0.5-1.3)$ & $1.6(1.0-2.6)$ & $0.8(0.5-1.3)$ \\
\hline \multicolumn{5}{|l|}{19} \\
\hline Depression & $1.1(0.6-1.7)$ & $1.4(0.7-2.7)$ & $1.0(0.6-1.7)$ & $1.3(0.6-2.7)$ \\
\hline Age (continuous) & $1.9(0.5-7.3)$ & $0.5(0.1-2.8)$ & $1.7(0.4-7.3)$ & $0.6(0.1-4.7)$ \\
\hline
\end{tabular}

Table 4. Socio-demographic characteristics and mean age at first sexual intercourse

The mean age at sexual debut was shown to increase with the increasing age of the respondents. The mean age at first sexual intercourse for early adolescents was $11.8 \pm$ 1.0. There was a statistically significant difference in mean age of sexual debut between early and late adolescents $(\mathrm{t}=4.42, \mathrm{p}=0.000)$. The girls-initiated sex earlier than the boys with a mean age of $13.4 \pm 2.9(t=3.16, p=0.001)$. Respondents from polygamous families initiated sexual intercourse at an earlier age than those from monogamous families. However, this finding was not statistically significant $(\mathrm{t}=1.82, \mathrm{p}>0.05)$. The students brought up by one parent-initiated sex at an earlier age $(t=3.28, \mathrm{p}=$ 0.000). Age of sex initiation increased as maternal education increased from secondary to tertiary education $(t=6.38, p=0.000)$. A similar pattern was also observed with the fathers' education, students whose fathers had only primary education-initiated sex earliest $12.1 \pm 3.4$, followed by those whose fathers had secondary education $12.5 \pm 2.8$ years, $(t=3.01, p=0.001)$. Respondents sharing room with parents or adult relations of opposite sex were found to have initiated sex earlier with a mean age of 12.3 \pm 1.9 years compared to those who did not $(t=6.10, \mathrm{p}=$ $0.000)$. 
Table 4. Socio-demographic characteristics and mean age at first sexual intercourse

\begin{tabular}{|c|c|c|c|c|c|}
\hline $\begin{array}{l}\text { Socio-demographic } \\
\text { variables }\end{array}$ & $\begin{array}{l}\text { No of } \\
\text { t-test }\end{array}$ & $\begin{array}{l}\text { Mean age at first } \\
\text { sexual intercourse }\end{array}$ & SD (1) & $\begin{array}{l}\text { Test } \\
\text { Statistic }\end{array}$ & P-value \\
\hline \multicolumn{6}{|l|}{ Age group* } \\
\hline $13-15$ & 265 & 11.8 & 1.0 & & \\
\hline $16-19$ & 143 & 13.5 & 4.2 & $\begin{array}{l}4.42, \\
\mathrm{df}=167\end{array}$ & 0.000 \\
\hline Total & 408 & & & & \\
\hline \multicolumn{6}{|l|}{ Sex* } \\
\hline Male & 202 & 12.1 & 1.4 & & \\
\hline Female & 206 & 14.5 & 2.9 & $\begin{array}{l}3.16 \\
\mathrm{df}=402\end{array}$ & 0.001 \\
\hline \multirow{2}{*}{\multicolumn{6}{|c|}{ Family* }} \\
\hline & & & & & \\
\hline Polygamous & 239 & 10.8 & 2.6 & & \\
\hline Monogamous & 169 & 13.0 & 3.2 & 1.82 & $\leq 0.05$ \\
\hline Total & 408 & & & & \\
\hline \multicolumn{6}{|l|}{ Family setting* } \\
\hline Living with both parents & 132 & 13.2 & 2.8 & & \\
\hline Living with one parent & 253 & 11.7 & 5.2 & & \\
\hline Other arrangements & 23 & 12.9 & 2.3 & $\begin{array}{l}3.28 \mathrm{df}= \\
402\end{array}$ & 0.000 \\
\hline \multirow{2}{*}{\multicolumn{6}{|c|}{ Mother's Education* }} \\
\hline & & & & & \\
\hline No Formal Education & 71 & 11.2 & 2.6 & & \\
\hline Primary Education & 46 & 12.1 & 2.3 & & \\
\hline Secondary Education & 179 & 13.9 & 3.3 & & \\
\hline Tertiary Education & 112 & 14.3 & 2.4 & $\begin{array}{l}6.38 \mathrm{df}= \\
402\end{array}$ & 0.000 \\
\hline \multirow{2}{*}{\multicolumn{6}{|c|}{ Father's Education* }} \\
\hline & & & & & \\
\hline No Formal Education & 62 & 11.4 & 3.8 & & \\
\hline Primary Education & 73 & 12.1 & 3.4 & & \\
\hline Secondary Education & 165 & 12.5 & 2.8 & & \\
\hline Tertiary Education & 108 & 14.2 & 2.7 & $\begin{array}{l}3.01 \mathrm{df}= \\
402\end{array}$ & 0.001 \\
\hline Total & 408 & & & & \\
\hline \multicolumn{6}{|c|}{ Sharing room with adult opposite sex* } \\
\hline Yes & 286 & 12.3 & 1.9 & & \\
\hline No & 122 & 13.6 & 2.7 & $\begin{array}{l}3.02 \mathrm{df}= \\
402\end{array}$ & 0.001 \\
\hline Total & 408 & & & & \\
\hline
\end{tabular}

\section{Discussion}

The main finding of this study revealed that early sexual debut is associated with depression in early and middle adolescents, but this association gradually disappears, and is actually reversed in late adolescence before adulthood. Even if early adolescents are already physically developed to engage safely in sexual activity, their cognitive, and emotional maturity develop more slowly than their physical maturity ${ }^{17}$. In late adolescence, emotional maturity has most often been reached, and being sexually active is no longer associated with self-reported depression; on the contrary, it was found that in 19-year-old boys it was not being sexually active that was associated with self-reported depression. To the best of the researchers' knowledge, none of the previous studies analysed the association between early sexual debut and depression.

The findings of this study concur with those of existing research establishing a link between early sexual activity and depression ${ }^{23}$. Data of this study further revealed that the relation between having experienced early sexual debut and self-reported depression is the stronger the younger the adolescent is. The association between self-reported depression and having experienced sexual intercourse diminished until, among adolescents aged 17 years, the association ceased to be significant. Among 19-year-old boys, the association became significant again, but in the opposite direction: depressed boys were less likely than their non-depressed peers to have experienced sexual intercourse. Being sexually inexperienced in an age when the vast majority has already engaged in intimate sexual relationships may trigger feelings of loneliness, social isolation, or sadness that may predispose to depression; but it is also possible that being depressed results in such difficulties in social relationships that sexual development is delayed. Among girls, the same observation was not statistically significant, even if the share of those who 
had experienced intercourse according to self-reported depression turned to the opposite from what was seen in early to middle adolescence. These findings support the theory of adolescent development suggesting that emotional maturity is reached later than physical and cognitive. According to developmental theory, self-reported depression should of course be negatively associated with experiencing sexual intercourse also among 19-yearolds. However, such was not the case in the data, probably due to a quite small sample of 19 -year-olds, $0.6 \%$ of the whole study population. What is more, it is uncommon for 19-year-old adolescents to be attending schools of the type at which the study was conducted. They are, for example, adolescents who have experienced severe illnesses or come from an immigrant background. Their adolescent development and mental health may deviate from the mainstream. Experience of early sexual debut for them may be similarly delayed. On the other hand, the group of 19-year-olds was also likely to include adolescents continuing to another secondary education after completing one.

The findings of this study are parallel for boys and girls. Yet as expected, there are slight differences. Among 14 and 15-year-olds, self-reported depression was a more significant factor to boys for experiencing sexual intercourse compared to girls. Because girls mature earlier than boys, they may also be emotionally readier for sexual intercourses at a younger age. Consequently, the data show that especially in the most immature cohort in this study, among the youngest boys, it is certainly pathological to engage in sexual activity. Moreover, sexual health services for adolescents tend to be directed primarily toward girls ${ }^{27}$.

The findings of this study revealed that adolescents sharing room with parents or adult relatives of opposite sex were found to have initiated sex earlier compared to those who did not. For instance, in a large family living in a one or two room apartment, the adolescents share room with parents or older relatives of opposite sex or house-help. They may sometimes observe their parents and older siblings indulge in sexual activity and may thereafter initiate sex earlier than they would have. These sexual debuts often occur as rape or incest with older relatives. This study showed that adolescents who did income-earning jobs also initiated sex earlier than those that did not. This finding agrees with the finding that adolescents who grow up in stable families with more resources are more likely to delay sexual intercourse ${ }^{28}$. This could be supported by the tendency to focus on socioeconomic disadvantage, positing that poor adolescents' limited opportunities reduce the opportunity costs of sexual activity and attendant consequences ${ }^{27}$. This study showed that the age of sex initiation increased as educational statuses of the parents increase. This report is in agreement with the findings in Nigerian studies that educational level of parents is one of the factors that contributed to the exposure to sexual intercourse. This finding agrees with the findings that one of the variables independently associated with sexual activity was lower educational level of parents. It is believed that the more educated parents are, the more they are equipped with information on adolescent sexuality and delay in sexual debut to transmit on to these adolescents ${ }^{29}$.

\section{Limitations and strengths of the study}

This study is based on self-reports of early sexual debut and is subject to social desirability bias due to the sensitive nature of some of the questions. Secondly, sexual behaviours such as age of sexual debut may be affected by recall bias. While the findings may not be representative of all adolescents from different socio-economic and demographic backgrounds in the country, the findings provide insight into the sexual behaviour of adolescents within a sub-set of the Nigerian society. A major strength of the present study is the high response rate $(100 \%)$ achieved. There was also an assessment of individual and family variables at the same time, thereby reducing the number of unmeasured covariates that could bias the findings.

\section{Conclusion}

Becoming sexually active is part of adolescent development, also, embarking on sexual activity very early in adolescent development is associated with self-reported depression. Trends in mean age at sexual debut among the respondents was assessed which was found to be associated with younger age, sharing rooms with parents, living with one parent, doing income earning jobs and low socio-economic status of parents. The finding that adolescents initiate sexual intercourse at an earlier age, underscores the importance of early intervention programs for 
this group. They may require more intensive sex education and special support to be able to protect themselves from engaging in sexual activity too early, before being emotionally ready for it. We therefore, recommend that formal comprehensive sex education programs targeted at delaying age at first sex should begin early in primary school before adolescents become sexually active. Efforts should be directed towards increasing the scope of parental communication strategies to reach all adolescents alongside promoting family stability.

\section{Disclosure statement}

No conflict of interest was reported by the authors.

\section{Funding}

None.

\section{References}

1. WHO. Reproductive health through schools in low income countries: an information brief Geneva. World Health Organization 2008. Available at http://whqlibdoc.who.int/Accessed on 2012 April 17.

2. Duru CB, Ubajaka, C, Nnebue CC, Ifeadike CO, Okoro OP. Sexual behaviour and practices among secondary school adolescents in Anambra State, Nigeria. Afrimedic Journal. 2010; 1(2): 22-27

3. Cortez R, Saadat S, Marinda E, Odutolu. O. Adolescents fertility and sexual health in Nigeria, 2016. World Bank Group Health, Nutrition and population. Page 17 of 41 ScholarOne, 375 Greenbrier Drive, Charlottesville, VA, 22901 Workflow 0 For Peer Review 17.

4. Harden KP. True love waits? A sibling-comparison study of age at first sexual intercourse and romantic relationships in young adulthood. Psychological Science. 2012;23(11):1324-1336. doi:10.1177/0956797612442550. 5. Richter L, Mabaso M, Ramjith J, Norris A. Early sexual debut: Voluntary or coerced? Evidence from longitudinal data in South Africa - the Birth to Twenty Plus study. The South African Medical Journal, 2015; 2 (3): 23-28.

6. Maharaj P, Munthree C, Coerced. First sexual intercourse and selected reproductive health outcomes among young women in Kwazulu-Natal, South Africa Journal of Biosocial Science, 200739 (2): 231-244.

7. Santelli JS, Lowry R, Brener ND, Robin L. The association of sexual behaviors with socioeconomic status, family structure, and race/ethnicity among US adolescents. American Journal of Public Health. 2000;90(10):1582-1588.
8. Davis EC, Friel LV. Adolescent sexuality: Disentangling the effects of family structure and family context. Journal of Marriage and Family. 2001;63(3):669-681.

9. Marteleto L, Lam D, Ranchhod V. Sexual Behaviour, Pregnancy, and Schooling among Young People in Urban South Africa. Stud Fam Plann. 2008; 39(4): 351-368.

10. Edgardh K. Sexual behaviour and early coitarche in a national sample of 17-year-old Swedish boys. Acta Paediatrica, 2002. 91(9), 985-991. doi: 10.1080/080352502760272704 11. Heidmets Samm, Sisask Kõlves, Aasvee Värnik. Sexual behavior, depressive feelings, and suicidality among Estonian school children aged 13 to 15 years. Crisis. 2010;31(3):128-36. doi: 10.1027/0227-5910/a000011.

12. Ekundayo OJ, Chair EJ, Aban IB, Bachmann LH, Ehiri JE, Kempf MC. Factors associated with sexual debut and depression among adolescents in rural Jamaica. A Dissertation submitted to the graduate faculty of The University of Alabama at Birmingham, in partial fulfilment of the requirements for the degree of Doctor of Public Health. 2007 UMI Number: 3265456. Retrieved from http://www.teappoyo.com/bibliografia/Ekundayo, $\% 200 . \% 20 J . \% 20 \% 282007 \% 29 . . p d f$

13. Mmbaga EJ, Leonard F, Leyna GH. Incidence and Predictors of Adolescent's Early Sexual Debut after Three Decades of HIV Interventions in Tanzania: A Time to Debut Analysis. 2012. PLoS One. 7(7): e41700. https://doi.org/10.1371/journal.pone.0041700

14. World Bank Group. Adolescent Sexual and Reproductive Health Challenges and Universal Health Coverage: Report Series. 2014. Retrieved from http://www. worldbank.org/en/topic/health/publication/adolescent-sexual-andreproductive-health-challenges-and-universal-health-coverage-report-series.

15. World Bank Group Adolescent Sexual and Reproductive Health Challenges and Universal Health Coverage: Report Series. Retrieved from http:/ /www.worldbank.org/ en/topic/health/publication/adolescent-sexual-andreproductive-health-challenges-and-universal-health-coverage-report-series. Page 18 of 41 Scholar One, 375 Greenbrier Drive, Charlottesville, VA, 22901 Workflow 0 For Peer Review 18

16. Sabia JJ, Rees DI. The Effect of Sexual Abstinence on Females' Educational Attainment. Demography. 2009 Nov; 46(4): 695-715.

17. Starr LR, Davila J. Clarifying co-rumination: Associations with internalizing symptoms and romantic involvement among adolescent girls. Journal of Adolescence, 2009. $32,19-37$. 
18. Peterson AC, Compas BE, Brooks-Gunn J, Stemmler M, Ey S, Grant KE. Depression in Adolescence. Am Psychol. 1993; 48:155-168.

19. Harrington R, Rudge H, Rutter M, Pickles A, Hill J. Adult outcomes of childhood and adolescent depression. Arch gen Psychiatry. 1990; 47:465-73.

20. Moshman D. Adolescent rationality and development: Cognition, morality, and identity ( $3^{\text {rd }}$ ed.). New York, NY: Psychology Press. 2011.

21. Warren CW, Santelli JS, Everett SA. Sexual behavior among US high school students, 1990-1995. Fam Plann Perspect. 1998; 30:170-172.

22. Kovacs M. Children's Depression Inventory. North Tonawanda, NY. Multi-Health Systems. 1992. pp. 1-101. 23. Rivera CL, Bernal G, Rossello J. The Children Depression Inventory (CDI) and the Beck Depression Inventory (BDI): Their validity as screening measures for major depression in a group of Puerto Rican adolescents. Int J Clin Health Psychol. 2005;5: 485-498.

24. Steinberg L. Cognitive and affective development in adolescence. Trends in Cognitive Sciences, 2005.9 (2), 69-74. doi:10.1016/j.tics.2004.12.005 [Google Scholar]).
25. Hallfors DD, Waller MW, Ford CA, Halpern CT, Brodish PH., Iritani B. Adolescent depression and suicide risk: Association with sex and drug behavior. American Journal of Preventive Medicine, 27(3), 224-31. doi: 10.1016/j. amepre.2004.06.001;

26. Avery L, Lazdane G. What do we know about sexual and reproductive health of adolescents in Europe? The European Journal of Contraception \& Reproductive Health Care, 15. 2010 (S2), S54-S66. doi:10.3109/13625187.2010.533 007).

27. Price M, Hyde J. When two isn't better than one: Predictors of early sexual activity in adolescence using a cumulative risk model. Journal of Youth and Adolescence, 2009;38(8): 1059-1071.

28. Regan P, Durvasula R, Howell L, Ureno O, Rea M. Gender, ethnicity, and the developmental timing of first sexual and romantic experiences. SocialBehavior and Personality: An International Journal, 2004; 32, 667-676. DOI: https://doi.org/10.2224/sbp.2004.32.7.667.

29. Slap GB, Lot L, Huang B, Daniyam CA, Zink TM, Succop PA. Sexual behaviour of adolescents in Nigeria: cross sectional survey of secondary school students. BMJ. 2003 Jan 4;326 (7379):15. 